\title{
In Vitro impairment of whole blood coagulation and platelet function by hypertonic saline hydroxyethyl starch
}

Alexander A Hanke ${ }^{1 *}$, Stephanie Maschler ${ }^{2}$, Herbert Schöchl ${ }^{3}$, Felix Flöricke ${ }^{1}$, Klaus Görlinger ${ }^{4}$, Klaus Zanger $^{5}$, Peter Kienbaum ${ }^{2}$

\begin{abstract}
Background: Hypertonic saline hydroxyethyl starch $(\mathrm{HH})$ has been recommended for first line treatment of hemorrhagic shock. Its effects on coagulation are unclear. We studied in vitro effects of HH dilution on whole blood coagulation and platelet function. Furthermore 7.2\% hypertonic saline, 6\% hydroxyethylstarch (as ingredients of $\mathrm{HH}$ ), and $0.9 \%$ saline solution (as control) were tested in comparable dilutions to estimate specific component effects of $\mathrm{HH}$ on coagulation.

Methods: The study was designed as experimental non-randomized comparative in vitro study. Following institutional review board approval and informed consent blood samples were taken from 10 healthy volunteers and diluted in vitro with either HH (HyperHaes ${ }^{\circledR}$, Fresenius Kabi, Germany), hypertonic saline (HT, 7.2\% NaCl), hydroxyethylstarch (HS, HAES6\%, Fresenius Kabi, Germany) or $\mathrm{NaCl} 0.9 \%$ (ISO) in a proportion of 5\%, 10\%, 20\% and $40 \%$. Coagulation was studied in whole blood by rotation thrombelastometry (ROTEM) after thromboplastin activation without (EXTEM) and with inhibition of thrombocyte function by cytochalasin D (FibTEM), the latter was performed to determine fibrin polymerisation alone. Values are expressed as maximal clot firmness (MCF, [mm]) and clotting time $(\mathrm{CT},[\mathrm{s}])$. Platelet aggregation was determined by impedance aggregrometry (Multiplate) after activation with thrombin receptor-activating peptide 6 (TRAP) and quantified by the area under the aggregation curve (AUC [aggregation units (AU)/min]). Scanning electron microscopy was performed to evaluate HyperHaes induced cell shape changes of thrombocytes.

Statistics: 2-way ANOVA for repeated measurements, Bonferroni post hoc test, $p<0.01$.

Results: Dilution impaired whole blood coagulation and thrombocyte aggregation in all dilutions in a dose dependent fashion. In contrast to dilution with $\mathrm{ISO}$ and $\mathrm{HS}$, respectively, dilution with $\mathrm{HH}$ as well as $\mathrm{HT}$ almost abolished coagulation (MCF EXTEM from $57.3 \pm 4.9 \mathrm{~mm}$ (native) to $1.7 \pm 2.2 \mathrm{~mm}$ ( $\mathrm{HH} 40 \%$ dilution; $\mathrm{p}<0.0001$ ) and to $6.6 \pm 3.4 \mathrm{~mm}$ (HT 40\% dilution; $\mathrm{p}<0.0001$ ) and thrombocyte aggregation (AUC from $1067 \pm 234 \mathrm{AU} / \mathrm{mm}$ (native) to $14.5 \pm 12.5 \mathrm{AU} / \mathrm{mm}$ ( $\mathrm{HH} 40 \%$ dilution; $\mathrm{p}<0.0001$ ) and to $20.4 \pm 10.4 \mathrm{AU} / \mathrm{min}$ (HT 40\% dilution; $\mathrm{p}<$ 0.0001 ) without differences between HH and HT (MCF: $p=0.452$; AUC: $p=0.449$ ).

Conclusions: $\mathrm{HH}$ impairs platelet function during in vitro dilution already at $5 \%$ dilution. Impairment of whole blood coagulation is significant after $10 \%$ dilution or more. This effect can be pinpointed to the platelet function impairing hypertonic saline component and to a lesser extend to fibrin polymerization inhibition by the colloid component or dilution effects.

Accordingly, repeated administration and overdosage should be avoided.
\end{abstract}

\footnotetext{
* Correspondence: hanke.alexander@mh-hannover.de

'Department of Anaesthesiology and Intensive Care Medicine, Hannover Medical School, Germany

Full list of author information is available at the end of the article
}

\section{() Biomed Central}

(c) 2011 Hanke et al; licensee BioMed Central Ltd. This is an Open Access article distributed under the terms of the Creative Commons Attribution License (http://creativecommons.org/licenses/by/2.0), which permits unrestricted use, distribution, and reproduction in any medium, provided the original work is properly cited. 


\section{Background}

Normovolemia and sufficient coagulation capacity are major goals during early resuscitation of traumatized patients with hemorrhagic shock. Nevertheless, significant morbidity and mortality are related to coagulopathy due to loss and consumption of coagulation factors as well as volume substitution induced hemodilution. After patient admission to the emergency care department definite strategies have been established to improve outcome after severe hemorrhagic shock [1] including transfusion of packed red blood cell concentrates, fresh frozen plasma, cryoprecipitate and coagulation factor concentrates. However, during the prehospital period various crystalloids and colloids have been suggested for treatment of hemorrhagic shock. Whatever fluid is administered, there is at least a dose dependent dilution of coagulation factors which is associated with a further impairment of coagulation.

Recently, small volume resuscitation by intravenous administration of small amounts of hypertonic saline hydroxyethyl starch has been introduced for rapid restoration of normovolemia following severe trauma. However, both hypertonic sodium chloride as well as hydroxyethyl starch, impair coagulation and platelet function; the former by altering plasma clotting times and platelet aggregation [2], the latter by decreasing FVIII plasma concentration and by interference with fibrin polymerization and thus decreasing clot strength [3-6]. Nevertheless, in a porcine model of hemorrhagic shock and resuscitation, in general, the least effects on coagulation were observed following small volume resuscitation by administration of hypertonic saline hydroxyethyl starch for resuscitation [7]. Since small volume resuscitation was associated with alterations in the coagulation system in this animal model as well, we evaluated these complex effects on coagulation and thrombocyte function in vitro in human whole blood and tested the hypothesis that HyperHaes causes impaired whole blood coagulation and platelet function.

\section{Methods}

The study was designed as experimental non-randomized comparative in vitro study.

Following institutional review board approval (study number: 2953, University Hospital Düsseldorf) this study was conducted in accordance with the Helsinki Declarations and European Unions Convention on Human Rights and Biomedicine.

The guidelines for reporting non-randomized studies [8] were utilized in the drafting of this report.

\section{Blood samples}

Ten volunteers (six male/four female; average age 33.7 years (range: $26-42$ y)) of Caucasian origin participated in the study after oral and written information and written consent. All volunteers were healthy and free of medication. Blood was taken from a basilic vein using an 18gauge IV catheter and collected in both citrated and heparinzed tubes (Vacutainer, Becton Dickenson, Heidelberg, Germany).

\section{Sample preparation}

Blood was assigned to four different groups: Group A $(\mathrm{HH})$ : Hypertonic Saline Hydroxyethyl Starch (HyperHaes $^{\circledR}$, Fresenius Kabi, Bad Homburg, Germany); Group B (HT): $7.2 \%$ hypertonic sodium chloride solution; Group C (HS): 6\% hydroxyethyl starch (HAES 200/0.5 6\%, Fresenius Kabi, Bad Homburg, Germany); Group D (ISO): isotonic sodium chloride solution, serving as control group.

Blood samples were diluted with one of the four fluids (HH, HT, HS and ISO) in a fix proportion of 1:20 (5\% dilution), 1:10 (10\% dilution), 1:5 (20\% dilution), 1:2.5 ( $40 \%$ dilution) and the effects of dilution were compared to undiluted baseline values.

\section{Whole blood coagulation}

Whole blood coagulation was analyzed by rotation thrombelastometry (ROTEM, TEM international, Munich, Germany) in citrated whole blood samples. The technique has been described previously elsewhere [9-11]. In brief, ROTEM analyzes viscoelastic clot characteristics over time in activated whole blood and recognizes both the time course of clotting as well as the firmness of the resulting clot. The following commercially available tests were performed following the manufacturer's instructions: ExTEM (extrinsically activation by tissue factor) and FibTEM (extrinsically activation by tissue factor with addition of Cytochalasin D to inhibit platelet function and display fibrin polymerization only all tests Pentapharm, Munich, Germany). Since maximum clot firmness (MCF) in whole blood coagulation is mainly determined by platelet function and fibrin polymerization, while clotting times $(\mathrm{CT})$ are dependent on the speed of thrombin generation by clotting factors [10] the chosen parameters were: CT quantifying the time from beginning of the reaction until start of clot formation and MCF indicating clot stability at its highest degree.

Since samples for thrombelastometry are recommended to be analysed within two hours we used three ROTEM devices in parallel. Tests were performed in a standard sequence. ROTEM devices were chosen in a random order.

\section{Platelet function}

Platelet function was determined by multiple electrode aggregometry (MEA) using a novel multiple platelet 
function analyzer (Multiplate, Dynabyte, Munich, Germany, heparinized whole blood samples) following TRAP activation (thrombin activating peptide, TRAPtest, Dynabyte, Munich, Germany). The technique has been described previously elsewhere [11]. MEA utilizes single uses test cells. These cells contain two pairs of sensor wires extending into a 50\% diluted whole blood sample. Platelets are non adhaesive in resting state, but when activated stick to the sensor wires enhancing electrical impedance between wires. These impedance changes are recorded over a period of six minutes. Tests were performed regarding the manufacturer's instructions. As indicator for platelet function the area under the aggregation curve (AUC) was determined indicating overall platelet activity.

\section{Electron microscopy}

Scanning electron microscopy (SEM) was performed at 1:2000 and 1:5400 magnification on samples to evaluate effects of HyperHaes on the cell shape of the thrombocytes, using a Jeol 35 CF SEM and documentation by Orion 6.60 software (Orion Microscopy, Belgium).

\section{Statistical analysis}

A power analysis was performed based on results of a previously performed pilot test. Assuming an alpha error of 0.05 with a power of 0.95 we calculated a necessary sample size of 8 to show a significant effect of a $10 \%$ dilution of $\mathrm{HH}$ on MCF in the EXTEM test. Based on this calculation and to ensure reasonable data we have chosen to increase sample size to 10 .

After positive testing on normal distribution (Shapiro-Wilk-test) two way ANOVAs with Bonferroni post-hoc testing were performed for statistical analysis. The Statistical Package for Social Sciences (SPSS for Windows, 13.0, SPSS Inc., Chicago, IL., USA) and GraphPad Prism (Version 4.02, GraphPad Software Inc., San Diego, CA., USA) were used.

Values are displayed median \pm standard deviation. Considering a confidence interval of $99 \%$ an $\alpha$-error below 0.01 was considered to be statistically significant.

\section{Results}

\section{Whole blood coagulation}

Maximum clot firmness (MCF) in rotational thrombelastometry after extrinsically activation (ExTEM) showed a dose dependent impairment in all tested groups (figure 1A). In the control group ISO significant differences to baseline were found at $40 \%$ dilution ( $\mathrm{p}=$ 0.0001). In HH and HT significant influence on MCF was found when dilution was $\geq 10 \%(\mathrm{HH}$ : $\mathrm{p}=0.0009$; HT: $\mathrm{p}=0.0002)$. HS impaired MCF statistically significant when dilution was $\geq 20 \%$ ( $p=0.0033$ ). No differences were found between HH and HT $(p=0.452)$. HS $(\mathrm{p}<0.0001)$ and ISO $(\mathrm{p}<0.0001)$ showed less impairment of MCF compared to $\mathrm{HH}$.

Clotting times (CT) were statistically significant prolonged in all tested groups but the control group ISO (figure 1B). ISO did not induce significant differences as compared to baseline (ISO $40 \%$ dilution; $\mathrm{p}=0.128$ ). Significant influence on $\mathrm{CT}$ was found in $\mathrm{HH}$ and $\mathrm{HT}$ when dilution was 40\% $(\mathrm{HH}: \mathrm{p}=0.0003$; HT: $\mathrm{p}=$ 0.0002). HS already impaired CT statistically significant when dilution was $20 \%(\mathrm{p}=0.0022)$.

Fibrin polymerization (FibTEM) was statistically significant impaired in all tested groups (figure $1 \mathrm{C}$ ). In the control group (ISO) MCF as compared to baseline was significantly reduced when dilution was $\geq 20 \%$ ( $\mathrm{p}=$ $0.0005)$. Significant reduction of MCF by $\mathrm{HH}$ was found when dilution was $\geq 10 \%$ ( $\mathrm{p}<0.0001)$. HT significantly impaired MCF at $40 \%$ dilution $(\mathrm{p}=0.0006)$. MCF was significantly reduced by HS throughout the test beginning at $5 \%$ dilution $(\mathrm{p}=0.0033)$.

\section{Platelet function}

AUC was significantly impaired in all tested groups including ISO in a dose dependent fashion (figure 1D). As compared to baseline ISO and HS significantly decreased AUC when dilution was $\geq 10 \%$ (ISO: $\mathrm{p}=$ 0.0022; HS: $\mathrm{p}=0.0002$ ). AUC was significantly decreased in $\mathrm{HH}$ and $\mathrm{HT}$ in all tested dilutions beginning at 5\% dilution ( $\mathrm{HH}: \mathrm{p}=0.0001$; $\mathrm{HT}: \mathrm{p}=0.0014)$. Between $\mathrm{HH}$ and $\mathrm{HT}$ no significant differences were found ( $\mathrm{p}=0.449$ ) while impairment of platelet function in $\mathrm{HH}$ was pronounced compared to HS ( $\mathrm{p}=0.0011)$ and ISO ( $\mathrm{p}<0.0001)$.

\section{Electron microscopy}

Dilution with $\mathrm{HH}$ caused deformed platelets and large aggregates of platelets (figure 2). Since building of aggregates prohibits exact counting of platelets within these aggregates a quantification of morphological changes was impossible.

\section{Discussion}

$\mathrm{HH}$ significantly impairs whole blood coagulation and platelet function in a dose dependent fashion in vitro by reducing platelet function as well as fibrin polymerization. The mechanism can be attributed to the hypertonic saline component and is associated with a dehydration and activation of platelets leading to accumulation of thrombocytes as demonstrated by scanning electron microscopy.

$\mathrm{HH}$ is suggested for first line treatment in hemorrhagic shock. Since studies in trauma patients are always affected by an inhomogeneous cohort of patients we have chosen a model of in vitro dilution for standardization of study conditions to estimate the effects of 


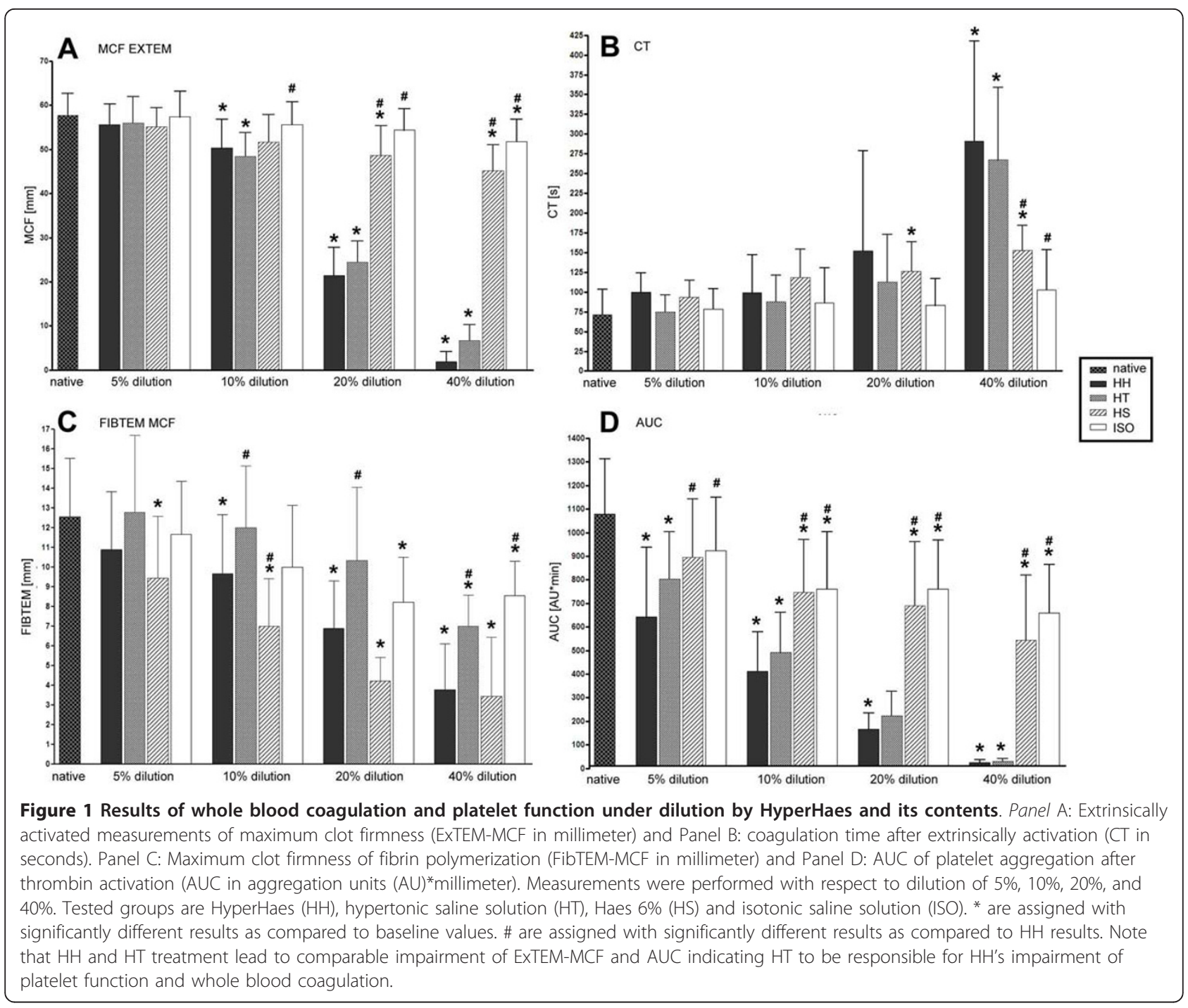

HyperHaes and to identify a possible coagulation impairing substance. Since our study was not designed to evaluate effects on circulatory conditions, we did not adapt dilution volumes of the different agents to possible hemodynamic potentials but in a fixed manner as compared to $\mathrm{HH}$ infusion alone. Furthermore the study cannot assess or predict effects on blood loss or outcome.

In vitro studies on coagulation are limited because complex hemostasis pathways cannot be simulated in a complete natural way. Interaction between primary and secondary hemostasis cannot be displayed in coagulation tests. Regular laboratory tests on coagulation use plasma as matrix for analysis. Therefore we decided to use rotational thrombelastometry and multiple platelet aggregation which assay whole blood as a more physiologically matrix to assess coagulation including platelet function. Furthermore thrombelastometry analyzes the end product of coagulation: the clot itself and its stability over time, which indicates clot building potential at the time of analysis. A dynamic time course of coagulation impairment and possible recovery from impairment cannot displayed in our study.

In vivo osmolarity is influenced by numerous factors. Osmolarity in dogs after a $50 \%$ blood volume withdrawal and following infusion of $4 \mathrm{ml}^{*} \mathrm{~kg}^{-1}$ hypertonic $\mathrm{NaCl}$ (2400 mOsmol*l ${ }^{-1}$, which is comparable to HyperHaes) led to an increase of plasma osmolarity from $307 \mathrm{mOs}-$ $\mathrm{mol}^{* \mathrm{l}^{-1}}$ to $333 \mathrm{mOsmol}^{* \mathrm{l}^{-1}}$ within 30 minutes [11]. Estimating average plasma osmolarity of $300 \mathrm{mOsmol}^{* \mathrm{l}^{-1}}$ and an osmolarity of $2400 \mathrm{mOsmol}^{* \mathrm{l}^{-1}}$ for HyperHaes in vitro dilution by $5 \%$ would suggest a resulting osmolarity of approximately $405 \mathrm{mOsmol}^{*} \mathrm{l}^{-1}$ which is already markedly above physiological levels. These in vitro high osmolarity conditions could compromise the translation of the results into clinical settings. Nevertheless, it 

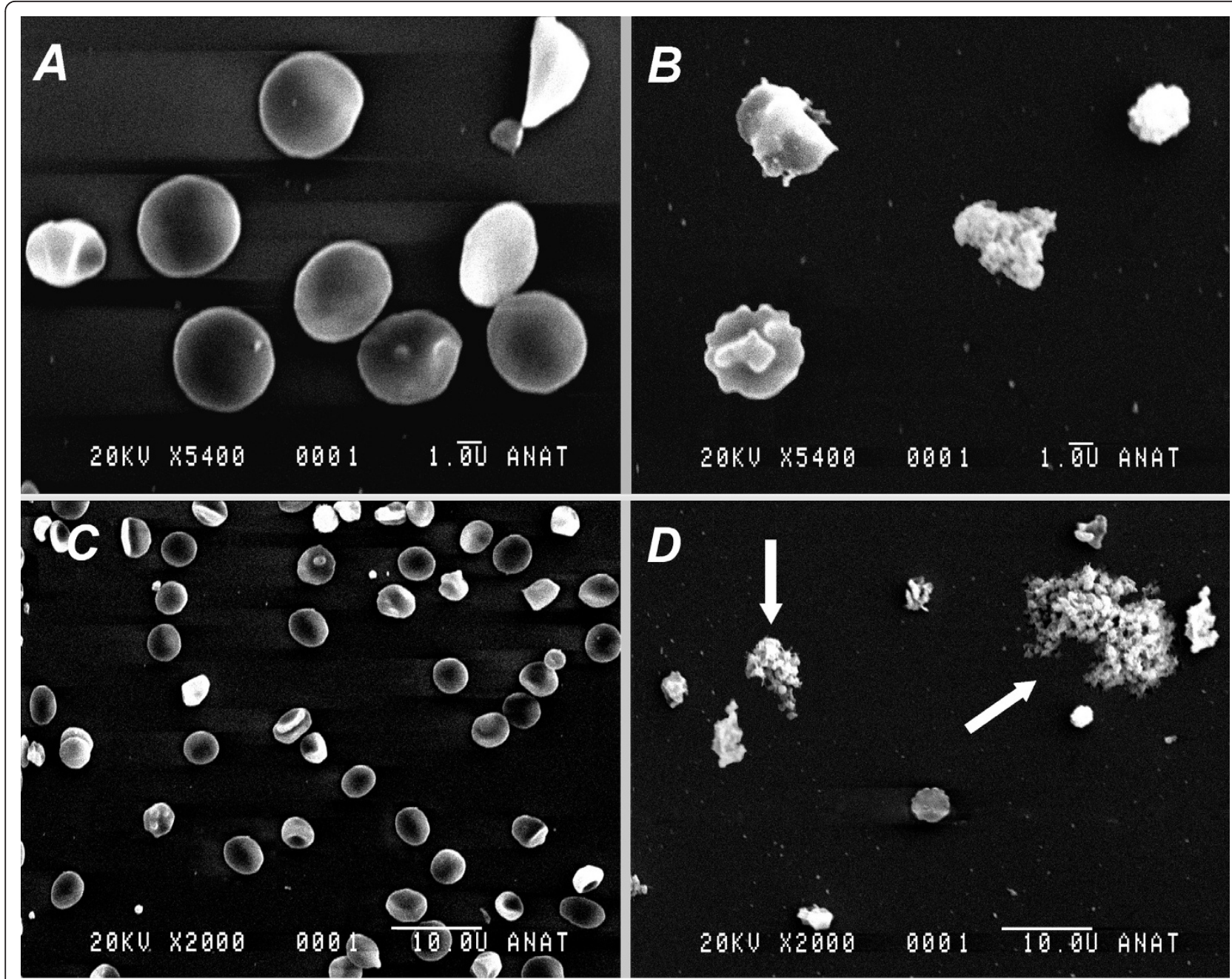

Figure 2 Scanning electron microscopy of native platelets (panels A and C) and platelets from blood after $40 \%$ dilution HyperHaes (panels B and D) in 5400fold (panels A and B) and 2000fold (panels C and D) magnification. Representative scans demonstrate deformed platelets, spreading activated platelets (panel B), as well as large aggregates of activated platelets (arrows in panel D). Note small bars on the lower right side of each panel indicating length of $1.0 \mathrm{U}=1 \mu \mathrm{m}$ (panels $\mathrm{A}$ and $\mathrm{B}$ ) and $10.0 \mathrm{U}=10 \mu \mathrm{m}$ (panels $\mathrm{C}$ and D), respectively.

remains unclear if compensation mechanisms are able to adjust osmolarity before interfering with platelets. In a different setting of acidosis and diminished coagulation laboratory parameters did not return to normal after compensation of acidosis [12]. Furthermore it could be possible that repeated administration or overdosage of $\mathrm{HH}$ could account for a non-physiological increase in osmolarity exceeding possibilities of compensation.

Normal blood volume in adults may be estimated to be $70-80 \mathrm{ml} / \mathrm{kg}$ bodyweight. Accordingly, the recommended $\mathrm{HH}$ dose of $4 \mathrm{ml} / \mathrm{kg}$ bodyweight in patients with hemorrhagic shock yields a hemodilution of 1:17.5 (5.7\%) to $1: 20$ (5\%). Since this mirrors normal conditions without blood loss we have chosen a $5 \%$ dilution as lowest degree of dilution for our study. Blood loss would lead to a further reduction in circulating blood volume and thus to a relatively increased portion of infused $\mathrm{HH}$ per $\mathrm{ml}$ blood volume resulting in an increased test agent/blood ratio, ergo to greater dilution. Blood loss of $50 \%$ blood volume then would lead to approximately $1: 10(10 \%)$ dilution, 75\% blood loss would account for a 1:5 (20\%) dilution and $40 \%$ dilution would be comparable to $87.5 \%$ blood loss. With respect to this consideration increasing blood loss would lead to increasing relative overdosage accounting for possible enhancement of otherwise induced coagulation disorders.

Even $5 \%$ whole blood dilution with $\mathrm{HH}$ significantly impaired platelet function. This effect on thrombocytes cannot be adequately detected in whole blood coagulation. However, MCF was affected in all samples with $\geq 10 \%$ dilution and $\mathrm{CT}$ prolongation finally occurred when dilution was $40 \%$. Maximum clot firmness in 
whole blood coagulation is basically determined by platelet function and fibrin polymerization, while clotting times are dependent on the speed of thrombin generation by clotting factors [13]. Thus, $\mathrm{HH}$ affected platelet function and fibrin polymerization in a more severe way than action of clotting factors. Responsible for interference with fibrin polymerization of $\mathrm{HH}$ is its HS portion, since we demonstrate a comparable impairment of fibrin clot firmness by $\mathrm{HH}$ as compared to HS. It is well known that HS inhibits fibrin polymerization [14-18]. Our data are consistent with these findings. This effect is most likely caused by dilution of fibrinogen [19] and decreased FXIIIa-mediated fibrin cross linking $[14,15]$. However, the precise molecular mechanism still remains unclear.

The mechanism of action of $\mathrm{HH}$ to improve blood pressure is based on mobilization of extravasal fluids along an osmotic gradient by intavasal administration of $\mathrm{HH}[20]$. We suspected this intavasal hyperosmolarity also to be one possible mechanism of interaction between the hypertonic solution and platelets leading to dehydrated and functionless thrombocytes. Platelets treated with and without $\mathrm{HH}$ were examined by electron microscopy. In the HH dilution deformed single platelets as well as large aggregates of activated platelets can be seen (figure 2). Such aggregates could account for a loss of platelet function and in vivo could lead to an obstruction of small vessels leading to a reduced platelet count as well. A detection of such aggregates after in vivo administration of hypertonic saline solution has not been done to date and would be of great interest concerning our findings.

In experimental settings controversial effects of $\mathrm{HH}$ on coagulation have been described. In animal models of uncontrolled hemorrhage treatment with hypertonic saline led to an aggravation of hemorrhage [21-23]. In these studies only hypertonic saline was studied while HS was not administered alone or in combination with hypertonic saline. In a recent study in a model of uncontrolled hemorrhage in pigs after liver injury less hemorrhage after $\mathrm{HH}$ administration was observed as compared to the use of colloids alone [7]. However, in this study red blood cells collected by an automated cell saver were simultaneously to the test agent infused. As a consequence the dosage of the hypertonic and hyperoncotic agent was reduced in a relative way by the parallel infusion of red blood cells which could have weakened the coagulation impairing effect of $\mathrm{HH}$. Despite this, to reflect comparable hemodynamic potential greater volumes of colloid infusions were admitted leading to a higher dilution of clotting factors in the control group. Since red blood cell concentrates or cell saver blood is available in the hospital only the settings of this study are more comparable to an admission in the emergency room or the operating theatre than to a preclinical situation. As a consequence conclusions on the influence of these solutions on coagulation and blood loss in a preclinical situation should be drawn with caution.

Another hazard might occur when hypertonic saline is used in combination with large doses of colloids due to additional risks of adverse effects of colloids itself as for example anaphylactic reactions or reduction of kidney function which also have to be considered [24-27].

In different clinical situations of major blood loss such as penetrating chest trauma [28], patients undergoing cardiac surgery $[29,30]$, or vascular surgery [31-33] studies indicating beneficial effects on outcome have been published. However, results of meta-analysises showed if any only minor improvement of survival no matter if hypertonic saline solution is used exclusively or in combination with colloids [34-36].

Our results indicate $\mathrm{HH}$ to cause a dose dependent impairment of platelet function and whole blood coagulation. However, these effects appear to be small in dilutions comparable to expected dilution after treatment of shock when the circulating blood volume is not reduced. From a different point of view this implicates that considering a small therapeutic index the risk of overdosage seems to be high and should be strictly avoided. Whether this also accounts for repeated admission and length of a time interval for possible safe repeated administration of $\mathrm{HH}$ cannot be assessed in the present study and may be addressed in future investigations.

Furthermore, the recommended dosage of $\mathrm{HH}$ is calculated with respect to bodyweight. In clinical situations variables as for example body weight can be assessed easily. In preclinical situations it is much more difficult to assess the patient's bodyweight which could lead to overdosage per se.

We calculated our dilution series to compare resulting dilution effects to $\mathrm{HH}$ treatment at different degrees of severe blood loss. Since we found greater effects on platelets with increasing dilution due to higher drug levels, we suspect $\mathrm{HH}$ treatment to show increasing negative effects on coagulation and platelet function with increasing blood loss due to possible relative overdosage. $\mathrm{HH}$ is designed to help stabilizing circulatory conditions in these situations. This implicates that dosage in patients with higher blood loss should be calculated with care, repeated administration should be avoided and the physician should be aware of increasing coagulopathy.

Since it remains questionable if our findings can be transferred into clinical settings clinical studies are necessary to evaluate such issues.

\section{Conclusions}

HyperHaes as an example for hypertonic saline hydroxyethyl starch solution impairs whole blood coagulation 
and platelet function in a dose dependent fashion. Responsible for impairment of platelet function is the hypertonic saline component, while interference with fibrin polymerization is based on both colloid and dilution effects.

Overdosage and relative overdosage due to underestimated blood loss should be avoided and increasing coagulopathy considered in a subtle manner.

\section{Acknowledgements}

The presented study was performed on departmental sources without external funding.

\section{Author details}

${ }^{1}$ Department of Anaesthesiology and Intensive Care Medicine, Hannover Medical School, Germany. ${ }^{2}$ Department of Anaesthesiology, University Hospital Düsseldorf, Germany. ${ }^{3}$ Department of Anaesthesiology and Intensive Care, AUVA Trauma Hospital, Salzburg, Austria. ${ }^{4}$ Department of Anaesthesiology and Intensive Care Medicine, University Hospital Essen, Germany. ${ }^{5}$ Institute for Anatomy II, University Hospital Düsseldorf, Germany.

\section{Authors' contributions}

$\mathrm{AH}$ conceived of the study, carried out the experiments, performed statistical analysis of the results and drafted the manuscript. SM performed essential laboratory work. HS, FF and KG participated in the design of the study and interpretation of the results. KZ performed electron microscopy. PK participated in study design and coordination and helped to draft the manuscript. All authors read and approved the final manuscript.

\section{Competing interests}

Dr. Hanke and Dr. Schöchl received speaker fees from CSL Behring, Marburg, Germany, Dr. Görlinger received speaker fees from CSL Behring, Marburg, Germany, and TEM international, Munich, Germany.

Received: 18 October 2010 Accepted: 10 February 2011 Published: 10 February 2011

\section{References}

1. Spinella PC, Holcomb JB: Resuscitation and transfusion principles for traumatic hemorrhagic shock. Blood Rev 2009, 23:231-240.

2. Reed RL, Johnston TD, Chen Y, Fischer RP: Hypertonic saline alters plasma clotting times and platelet aggregation. J Trauma 1991, 31:8-14.

3. de Jonge $\mathrm{E}$, Levi M: Effects of different plasma substitutes on blood coagulation: a comparative review. Crit Care Med 2001, 29:1261-1267.

4. de Jonge $E$, Levi M, Buller HR, Berends F, Kesecioglu J: Decreased circulating levels of von Willebrand factor after intravenous administration of a rapidly degradable hydroxyethyl starch (HES 200/0.5/ 6) in healthy human subjects. Intensive Care Med 2001, 27:1825-1829.

5. Innerhofer P, Fries D, Margreiter J, Klingler A, Kühbacher G, Wachter B, Oswald E, Salner E, Frischut B, Schobersberger W: The effects of perioperatively administered colloids and crystalloids on primary platelet-mediated hemostasis and clot formation. Anesth Analg 2002, 95:858-65

6. Treib J, Haass A, Pindur G, Grauer MT, Wenzel E, Schimrigk K: All medium starches are not the same: influence of the degree of hydroxyethyl substitution of hydroxyethyl starch on plasma volume, hemorrheologic conditions, and coagulation. Transfusion 1996, 36:450-455.

7. Haas T, Fries D, Holz C, Innerhofer P, Streif W, Klingler A, Hanke A, VelikSalchner C: Less impairment of hemostasis and reduced blood loss in pigs after resuscitation from hemorrhagic shock using the small-volume concept with hypertonic saline/hydroxyethyl starch as compared to administration of $4 \%$ gelatin or $6 \%$ hydroxyethyl starch solution. Anesth Analg 2008, 106:1078-86

8. Reeves BC, Gaus W: Guidelines for reporting non-randomised studies. Forsch Komplementarmed Klass Naturheilkd 2004, 11(Suppl1):40-52

9. Franz RC: ROTEM analysis: a significant advance in the field of rotational thrombelastography. S Afr J Surg 2009, 47:2-6.
10. Gorlinger K, Jambor C, Dirkmann D, Dusse F, Hanke A, Adamzik M, Hartmann M, Philipp S, Weber AA, Rahe-Meyer N: Platelet function analysis with point-of-care methods. Herz 2008, 33:297-305.

11. Velasco IT, Pontieri V, Rochae Silva M Jr, Lopes OU: Hyperosmotic $\mathrm{NaCl}$ and severe hemorrhagic shock. Am J Physiol 1980, 239(5):664-673.

12. Martini WZ, Dubick MA, Wade CE, Holcomb JB: Evaluation of trishydroxymethylaminomethane on reversing coagulation abnormalities caused by acidosis in pigs. Crit Care Med 2007, 35(6):1568-1574.

13. Lang T, von Depka M: Possibilities and limitations of thrombelastometry/graphy. Hamostaseologie 2006, 26:20-29.

14. Nielsen VG: Colloids decrease clot propagation and strength: role of factor XIII-fibrin polymer and thrombin-fibrinogen interactions. Acta Anaesthesiol Scand 2005, 49(8):1163-1171.

15. Nielsen VG: Effects of PentaLyte and Voluven hemodilution on plasma coagulation kinetics in the rabbit: role of thrombin-fibrinogen and factor XIII-fibrin polymer interactions. Acta Anaesthesiol Scand 2005, 49(9):1263-1271.

16. Fries D, Haas T, Klingler A, Streif W, Klima G, Martini J, Wagner-Berger $H$, Innerhofer P: Efficacy of fibrinogen and prothrombin complex concentrate used to reverse dilutional coagulopathy-a porcine model. Br J Anaesth 2006, 97(4):460-467.

17. Fries $D$, Innerhofer $P$, Reif $C$, Streif $W$, Klingler $A$, Schobersberger $W$, VelikSalchner C, Friesenecker B: The effect of fibrinogen substitution on reversal of dilutional coagulopathy: an in vitro model. Anesth Analg 2006, 102(2):347-351.

18. Brinkman AC, Romijn JW, van Barneveld LJ, Greuters S, Veerhoek D, Vonk $A B$, Boer C: Profound Effects of Cardiopulmonary Bypass Priming Solutions on the Fibrin Part of Clot Formation: An Ex Vivo Evaluation Using Rotation Thromboelastometry. J Cardiothorac Vasc Anesth 2010.

19. Fries D, Innerhofer P, Klingler A, Berresheim U, Mittermayr M, Calatzis A, Schobersberger $W$ : The effect of the combined administration of colloids and lactated Ringer's solution on the coagulation system: an in vitro study using thrombelastograph coagulation analysis (ROTEG). Anesth Analg 2002, 94:1280-1287.

20. Kreimeier U, Messmer K: Small-volume resuscitation: from experimental evidence to clinical routine. Advantages and disadvantages of hypertonic solutions. Acta Anaesthesiol Scand 2002, 46:625-638.

21. Gross D, Landau EH, Assalia A, Krausz MM: Is hypertonic saline resuscitation safe in 'uncontrolled' hemorrhagic shock? J Trauma 1988, 28:751-756.

22. Gross D, Landau EH, Klin B, Krausz MM: Quantitative measurement of bleeding following hypertonic saline therapy in 'uncontrolled' hemorrhagic shock. J Trauma 1989, 29:79-83.

23. Krausz MM, Landau EH, Klin B, Gross D: Hypertonic saline treatment of uncontrolled hemorrhagic shock at different periods from bleeding. Arch Surg 1992, 127:93-96.

24. Kreimeier U, Christ F, Kraft D, Lauterjung L, Niklas M, Peter K, Messmer K Anaphylaxis due to hydroxyethyl-starch-reactive antibodies. Lancet 1995, 346:49-50.

25. Laxenaire MC, Charpentier C, Feldman L: Anaphylactoid reactions to colloid plasma substitutes: incidence, risk factors, mechanisms. A French multicenter prospective study. Ann Fr Anesth Reanim 1994, 13:301-310.

26. Messmer KF: The use of plasma substitutes with special attention to their side effects. World J Surg 1987, 11:69-74.

27. Mounier P, Laroche D, Divanon F, Mosquet B, Vergnaud MC, Esse-Comlan A, Piquet MA, Bricard $\mathrm{H}$ : Anaphylactoid reactions to an injectable solution of a cremophor-containing solution of multivitamins. Therapie 1995, 50:571-573.

28. Wade CE, Grady JJ, Kramer GC: Efficacy of hypertonic saline dextran fluid resuscitation for patients with hypotension from penetrating trauma. $J$ Trauma 2003, 54:144-148.

29. Palmgren I, Hultman J, Houltz E: Perioperative transoesophageal echocardiography with low-dose dobutamine stress for evaluation of myocardial viability: a feasible approach? Acta Anaesthesiol Scand 1998, 42:162-166.

30. Sirieix D, Hongnat JM, Delayance $S$, et al: Comparison of the acute hemodynamic effects of hypertonic or colloid infusions immediately after mitral valve repair. Crit Care Med 1999, 27:2159-2165.

31. Christ F, Niklas M, Kreimeier U, Lauterjung L, Peter K, Messmer K: Hyperosmotic-hyperoncotic solutions during abdominal aortic aneurysm (AAA) resection. Acta Anaesthesiol Scand 1997, 41:62-70. 
32. Ragaller M, Muller M, Bleyl JU, Strecker A, Segiet TW, Ellinger K, Albrecht DM: Hemodynamic effects of hypertonic hydroxyethyl starch $6 \%$ solution and isotonic hydroxyethyl starch $6 \%$ solution after declamping during abdominal aortic aneurysm repair. Shock 2000, 13:367-373.

33. Shackford SR, Sise MJ, Fridlund PH, Rowley WR, Peters RM, Virgilio RW, Brimm JE: Hypertonic sodium lactate versus lactated ringer's solution for intravenous fluid therapy in operations on the abdominal aorta. Surgery 1983, 94:41-51.

34. Bunn F, Roberts I, Tasker R, Akpa E: Hypertonic versus near isotonic crystalloid for fluid resuscitation in critically ill patients. Cochrane Database Syst Rev 2004, CD002045.

35. Perel P, Roberts I: Colloids versus crystalloids for fluid resuscitation in critically ill patients. Cochrane Database Syst Rev 2007, CD000567.

36. Wade CE, Kramer GC, Grady JJ, Fabian TC, Younes RN: Efficacy of hypertonic $7.5 \%$ saline and $6 \%$ dextran-70 in treating trauma: a metaanalysis of controlled clinical studies. Surgery 1997, 122:609-616.

doi:10.1186/1757-7241-19-12

Cite this article as: Hanke et al: In Vitro impairment of whole blood coagulation and platelet function by hypertonic saline hydroxyethyl starch. Scandinavian Journal of Trauma, Resuscitation and Emergency Medicine 2011 19:12.

\section{Submit your next manuscript to BioMed Central} and take full advantage of:

- Convenient online submission

- Thorough peer review

- No space constraints or color figure charges

- Immediate publication on acceptance

- Inclusion in PubMed, CAS, Scopus and Google Scholar

- Research which is freely available for redistribution

Submit your manuscript at www.biomedcentral.com/submit 